\title{
Mathematical modelling of flow through thin curved pipes with application to hemodynamics
}

\author{
Arpan Ghosh
}


Linköping Studies in Science and Technology. Dissertations. No. 1988

\title{
Mathematical modelling of flow through thin curved pipes with application to hemodynamics
}

\author{
Arpan Ghosh
}

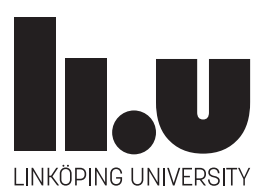

Division of Mathematics and Applied Mathematics Department of Mathematics

Linköping University

SE-581 83 Linköping, Sweden

Linköping 2019 
Linköping Studies in Science and Technology. Dissertations. No. 1988

Mathematical modelling of flow through thin curved pipes with application to hemodynamics

Copyright (c) Arpan Ghosh, 2019

Division of Mathematics and Applied Mathematics

Department of Mathematics

Linköping University

SE-581 83, Linköping, Sweden

arpan.ghosh@liu.se

https://liu.se/en/organisation/liu/mai/mtm

ISSN 0345-7524

ISBN 978-91-7685-073-2

Printed by LiU-Tryck, Linköping, Sweden 2019 


\section{Abstract}

The problem of mathematical modelling of incompressible flows with low velocities through narrow curvilinear pipes is addressed in this thesis. The main motivation for this modelling task is to eventually model the human circulatory system in a simple way that can facilitate the medical practitioners to efficiently diagnose any abnormality in the system. The thesis comprises of four articles.

In the first article, a two-dimensional model describing the elastic behaviour of the wall of a thin, curved, flexible pipe is presented. The wall is assumed to have a laminate structure consisting of several anisotropic layers of varying thickness. The width of the channel is allowed to vary along the pipe. The two-dimensional model takes the interactions of the wall with any surrounding material and the fluid flow into account and is obtained through a dimension reduction procedure. Examples of canonical shapes of pipes and their walls are provided with explicit systems of differential equations at the end.

In the second article, a one-dimensional model describing the blood flow through a moderately curved, elastic blood vessel is presented. The two-dimensional model presented in the first paper is used to model the vessel wall while linearized Navier-Stokes equations are used to model the flow through the channel. Surrounding muscle tissues and presence of external forces other than gravity are taken into account. The model is again obtained via a dimension reduction procedure based on the assumption of thinness of the vessel relative to its length. Results of numerical simulations are presented to highlight the influence of different factors on the blood flow.

The one-dimensional model described in the second paper is used to derive a simplified one-dimensional model of a false aneurysm which forms the subject of the third article. A false aneurysm is an accumulation of blood outside a blood vessel but confined by the surrounding muscle tissue. Numerical simulations are presented which demonstrate different characteristics associated with a false aneurysm.

In the final article, a modified Reynolds equation, along with its derivation from Stokes equations through asymptotic methods, is presented. The equation governs the steady flow of a fluid with low Reynolds number through a narrow, curvilinear tube. The channel considered may have large curvature and torsion. Approximations of the velocity and the pressure of the fluid inside the channel are constructed. These approximations satisfy a modified Poiseuille equation. A justification for the approximations is provided along with a comparison with a simpler case. 



\section{Populärvetenskaplig sammanfattning}

En av de viktigaste processerna i en mänsklig kropp är blodomloppet. Det är utsatt för många risker och därför är det viktigt att kunna diagnotisera fel i blodomloppet i god tid. Att formulera en enkel men realistisk matematisk modell för blodflödet som kan hjälpa till med diagnotisering är därmed viktigt. I den här avhandlingen, matematisk modellering av inkompressibelt flöde genom smala rör med tanke på blodkärl har studerats. Avhandlingen är en sammansättning av fyra artiklar.

I den första artikeln presenteras en tvådimensionell modell som beskriver det elastiska beteendet hos väggen av ett krökt flexibelt rör. Väggen antas ha en laminatstruktur bestående av flera lager av varierande tjocklek och elastiska egenskaper. Väggen antas också vara mycket mindre i tjocklek jämfört med kanalens bredd vilken tillåts variera längs röret. Den tvådimensionella modellen innehåller påverkan av omgivande material. Modellen har skapats via en procedur som kallas för dimensionreduktion där krökning och vridning av rörets axel samt laminatstrukturen hos väggen utgör de viktigaste utmaningarna. I artikeln presenteras också några exempel på modellen för enkelformer av röret.

I den andra artikeln presenteras en endimensionell modell som beskriver blodflödet genom ett måttligt krökt och elastiskt blodkärl. Modellen byggs på antagandet att kärlet är tunt jämfört med dess längd. Kärlväggen modelleras av den tvådimensionella modellen som presenteras i den första artikeln. Navier-Stokes ekvationer beskriver flöden av vätskor och de används här för att modellera flödet genom kanalen. Omgivande muskelvävnader och närvaro av yttre krafter tas med i beräkningen. Resultat av numeriska simuleringar presenteras för att markera påverkan av olika faktorer på blodflödet.

Den endimensionella modellen som beskrivs i den andra artikeln används för att härleda en förenklad endimensionell modell av en falsk aneurysm som utgör föremålet för den tredje artikeln. En falsk aneurysm är en ackumulering av blod utanför ett blodkärl men begränsat av den omgivande muskelvävnaden. Det är ett allvarligt medicinskt tillstånd som måste övervakas och under vissa omständigheter behandlas brådskande, vilket medför behovet av korrekt diagnos. Numeriska simuleringar presenteras som visar olika egenskaper hos en falsk aneurysm.

Reynolds ekvation beskriver tryckfördelning i tunna hinnor av vätskor. Stokes ekvationer beskriver långsamt flytande vätskor. I den sista artikeln presenteras en modifierad Reynoldsekvation tillsammans med dess härledning från Stokes ekvationer. Ekvationen reglerar det stabila flödet av en vätska med lågt Reynolds-tal genom ett krökt, smalt rör. Kanalen anses ha stor krökning och vridning. Approximation av hastighet och tryck hos vätskan inuti 
kanalen har konstruerats. En motivering till approximationerna ges tillsammans med en jämförelse med ett enklare fall. 


\section{Acknowledgements}

First and foremost, I would like to thank my supervisor Vladimir Kozlov for his unwavering support and guidance. He has always answered my questions with patience and I am grateful to him for his invaluable teachings. Next, I would like to thank my co-supervisors Matts Karlsson and David Rule for their support and encouragement. David has been a true teacher to me, and I thank him for the numerous discussions about mathematics and beyond.

I am sincerely grateful to my co-authors Sergei Nazarov and Fredrik Berntsson for their collaborations. It is truly a pleasure working with them.

The last five years have been a great learning period and I thank all my teachers who have contributed to my learning experience. I am also grateful to all my colleagues and especially the fellow $\mathrm{PhD}$ students at the department who have made for a pleasant workplace.

A few of the colleagues became wonderful friends to me over the years and I would like to take this opportunity to express my appreciation for their friendships. I thank Jolanta for always being a great company whenever we meet. My gratitude towards Samira for those weekly bike rides and the competitions. My appreciation towards Sonja for appreciating my jokes. Many thanks to Evgeniy for the drunk discussions and a great friendship. I am eternally grateful to Anna for her kind gestures and for sharing her passion for science with me. Big thanks to kompis Mikael for pushing me towards sporting adventures and for the laughs about the legends. And finally, a special thanks to Alexandra for being the best of friends whenever possible.

The final words of appreciation go to my family. I am grateful to Bishnupada Ghosh for guiding and inspiring me since my childhood. Lastly, I am thankful to my parents Lalkamal and Chhaya whose sacrifices and hard work made it possible for me to come this far. 



\section{List of Papers}

I. A. Ghosh, V. A. Kozlov, S. A. Nazarov, and D. Rule. A two-dimensional model of the thin laminar wall of a curvilinear flexible pipe. The Quarterly Journal of Mechanics and Applied Mathematics, 71(3):349-367, 2018.

Athuor's contribution: Writing the manuscript except Appendix A, major parts of the computations and analysis of the equations.

II. F. Berntsson, A. Ghosh, V.A. Kozlov, and S.A. Nazarov. A one dimensional model of blood flow through a curvilinear artery. Applied Mathematical Modelling, 63:633643, 2018.

Athuor's contribution: Writing the manuscript, numerical simulations, computations and analysis of the equations.

III. F. Berntsson, A. Ghosh, M. Karlsson, V.A. Kozlov, and S.A. Nazarov. A onedimensional asymptotic model of a false aneurysm. Submitted.

Athuor's contribution: Writing the manuscript, numerical simulations and computations.

IV. A. Ghosh, V. A. Kozlov, and S. A. Nazarov. Modified Reynolds equation for steady flow through a curved pipe. arXiv e-prints, page arXiv: 1901.01953, January 2019.

Athuor's contribution: Writing the manuscript, major parts of the computations and analysis of the equations. 



\section{Contents}

$\begin{array}{ll}\text { Abstract } & \text { i }\end{array}$

Populärvetenskaplig sammanfattning $\quad$ iii

Acknowledgements $\quad$ v

List of Papers $\quad$ vii

1 Introduction 1

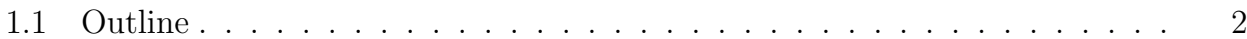

2 Elements of continuum mechanics 3

2.1 Theory of linear elasticity . . . . . . . . . . . . . . . . . 3

2.2 Fluid mechanics . . . . . . . . . . . . . . . . . . . . . . . 5

3 Curvilinear coordinates $\quad 7$

3.1 Rotation minimizing frame . . . . . . . . . . . . . . . . 7

3.2 Non-orthogonal frame . . . . . . . . . . . . . . . . . . . . 10

3.3 Volume and area elements . . . . . . . . . . . . . . . . . . . . . 11

4 Asymptotic analysis $\quad 13$

4.1 Asymptotic approximation . . . . . . . . . . . . . . . . . 13

4.2 Method of slow variation . . . . . . . . . . . . . . . . . . . . . . 14

References $\quad 15$

\section{INCLUDED PAPERS}

I. A two-dimensional model of the thin laminar wall of a curvilinear flexible pipe 17

II. A one dimensional model of blood flow through a curvilinear artery . . . . . 39 
III. A one-dimensional asymptotic model of a false aneurysm . . . . . . . . . . 53

IV. Modified Reynolds equation for steady flow through a curved pipe . . . . . . 69 


\section{Introduction}

Pipes transporting fluids are ubiquitous in our surroundings and hence a significant amount of research has been devoted to them. Fluid-flow through rigid pipes has been studied quite extensively, although, much of the literature is about straight pipes. In comparison, research on curved elastic pipes is not as abundant. The study of flow through elastic pipes is quite significant due to the numerous areas of application. Elastic tubes are found in various artificial mechanisms such as fuel or water transmission, vehicular systems, fire extinguishers etc. With the development of new, strong and light materials, the study of flexible tubes with thin, laminar walls acquire more importance. Moreover, elastic tubes also occur naturally in biological systems such as the respiratory system, the digestive system, the renal system, the cardiovascular system etc, see [5].

The circulatory system is one of the most important systems in the human body. It performs a number of essential tasks like supplying nutrition throughout the body, regulation of body temperature and fighting diseases. It is also susceptible to various kinds of diseases. Simulating the system with a reasonable model can be of great help in managing problems arising in the system. A good model can lead to early diagnosis of a problem and thereby enable a better management of the issue.

Substantial efforts have been made to model blood flow through blood vessels, see, for example, the monograph [3]. The complex arrangement of elastic tissues forming a blood vessel poses an increased difficulty in accurately modeling the interaction of blood flow with the vessel wall. The vessel walls have a laminate structure consisting of three layers of tissues (called adventitia, media and intima) having different composition and elastic properties, see [2]. Various one-dimensional models have been previously presented by employing simplifying assumptions on the geometry and structure of the blood vessels. For example, the models presented by $[4,8,11,14,15]$ are based on mass and momentum conservation laws together with a linear stationary tube law, while $[12,17]$ present models based on existing shell models coupled with Navier-Stokes equations. Navier equations coupled with Navier-Stokes equations have also been used to model blood flow, see [3, 13, 16]. However, majority of these works are based on cylinders having straight reference axes.

This thesis is aimed at the mathematical modelling of fluid flow through thin, curvilinear and compliant pipes. To model blood flow through curved vessels is the main motivation 
behind this study. This work consists of a collection of four articles, each addressing a different aspect of the modelling project.

\subsection{Outline}

This dissertation is comprised of two parts. The first part consists of four chapters which provide the fundamental concepts that have been used in the research that is being presented in this thesis. Chapter 1 introduces the subject matter of the thesis and provides the underlying motivation for the work presented. The dissertation is about the modelling of interaction between a fluid and a solid in a curved domain. In Chapter 2, some fundamental concepts from continuum mechanics are presented. The chapter is divided into two sections, the first of which is devoted to the theory of linear elasticity while the second addresses the theory of mechanics of fluids. Chapter 3 is dedicated to the description of the geometrical framework in which the modelling tasks have been performed. Lastly, in Chapter 4, a brief overview of the asymptotic method used for the modelling assignment is presented.

The second part consists of four research articles that have been produced as a result of the research. In Paper I, the derivation a two-dimensional model of the laminated, elastic wall of a curvilinear pipe is presented. Some examples of the model in the cases of simple geometric configurations are also provided in this paper. Paper II provides the derivation of a one-dimensional model of blood flow through a curved artery. A simple numerical scheme to solve the model equations is discussed and the results of some simulations with artificial data are also presented in this paper. Paper III presents an application of the one-dimensional model to the modelling of false aneurysms. In Paper IV, generalizations of Reynolds equation and Poiseuille equation are presented in the context of a thin curvilinear channel. Justification of the approximations generated by these equations is also provided in this paper. 


\section{Elements of continuum mechanics}

The model equations for the elastic wall of a pipe are derived from the principles of mechanics of linear elastic solids whereas the principles of fluid mechanics provide the model equations describing the flow in the channel inside the pipe. In this chapter, a brief overview of the concepts from continuum mechanics are presented which have been used in the papers included in this thesis. For a detailed introduction to the subject matter, the reader is referred to [7].

\section{$2.1 \quad$ Theory of linear elasticity}

Elasticity is the ability of a body to regain its original shape after being subjected to a deformation by some forces. The main quantity of interest for us in the modelling of a deformed elastic body is the displacement vector field, denoted here by $\mathbf{u}$, with respect to its reference state. The displacement gradient is the second order tensor $\nabla \mathbf{u}$. The deformation gradient quantifies the relative change in infinitesimal vectors under a deformation with respect to the reference state. It is given as

$$
\mathbf{D}=\mathbf{I}+\nabla \mathbf{u}
$$

Here $\mathbf{I}$ is the identity tensor.

The relative change in infinitesimal lengths in a deformed body with respect to its reference configuration is quantified by the so called the Cauchy-Green deformation tensor and is given by

$$
\mathbf{C}=\mathbf{D}^{T} \mathbf{D}=\mathbf{I}+\nabla \mathbf{u}+\nabla \mathbf{u}^{T}+\nabla \mathbf{u}^{T} \nabla \mathbf{u}
$$

The tensor $(\mathbf{C}-\mathbf{I}) / 2$ is termed as the Lagrange strain tensor. It provides a measure of deformation in a body by means of the relative displacements of points in the body with respect to its reference configuration.

If the deformations in an elastic body are infinitesimal, then the tensor $\mathbf{C}$ can be approximated by $\mathbf{I}+2 \varepsilon$ where

$$
\varepsilon=\frac{1}{2}\left(\nabla \mathbf{u}+\nabla \mathbf{u}^{T}\right)
$$


The tensor $\varepsilon$ is called the infinitesimal strain tensor.

Stress is a measure of the forces exerted by particles on their adjacent particles across an infinitesimal surface in a body. The Cauchy stress vector at a point across a surface passing through the point is defined as

$$
\mathbf{t}=\frac{\mathrm{d} \mathbf{F}}{\mathrm{d} S}
$$

where $\mathrm{d} \mathbf{F}$ is the infinitesimal resultant force across the infinitesimal surface $\mathrm{d} S$ containing the point.

The Cauchy stress principle is an axiom in classical continuum mechanics which states that the Cauchy stress vector at a point does not depend on the curvature of the surface at the concerned point, rather, only on its unit normal $\mathbf{n}$ at that point. This results in the stress vector having the expression

$$
\mathbf{t}=\boldsymbol{\sigma} \mathbf{n}
$$

The tensor field $\boldsymbol{\sigma}$ is known as the Cauchy stress tensor.

The field density of the resultant internal forces in a body is given by the quantity $\nabla \cdot \boldsymbol{\sigma}$ and applying Newton's second law of motion at each point in a body, one gets for time parameter $t$,

$$
\nabla \cdot \boldsymbol{\sigma}=\rho \frac{\mathrm{d}^{2} \mathbf{u}}{\mathrm{d} t^{2}}
$$

Here $\rho$ is the mass density of the body. The equation is called Cauchy's equation of motion.

A body is called linearly elastic or Hookean if it obeys Hooke's law, that is, the loading force at each point in the body is directly proportional to the relative displacement at the point with respect to the reference state of the body. This implies that the stress inside the body is a linear function of the strain at each point, with no stress in the absence of strain. Hence the 'constitutive equation' for the body is given as

$$
\sigma=\mathrm{T} \varepsilon
$$

where the fourth order tensor field $\mathbf{T}$ is called the elasticity tensor.

The constitutive equations along with Cauchy's equation of motion provide a system of hyperbolic partial differential equations for the relative displacement field $\mathbf{u}$, namely

$$
\frac{1}{2} \nabla \cdot\left(\mathbf{T}\left(\nabla \mathbf{u}+\nabla \mathbf{u}^{T}\right)\right)=\rho \frac{\mathrm{d}^{2} \mathbf{u}}{\mathrm{d} t^{2}}
$$

The preceding equation forms the basis of our model for the elastic part of the vessel. 


\subsection{Fluid mechanics}

While modelling the flow of a fluid through a channel, the main quantities of interest are the velocity field, say $\mathbf{v}$ and the hydrostatic pressure in the fluid body, say $p$ as functions of position vector $\mathbf{x}$ and time $t$. The fluid is characterised by its dynamic viscosity $\mu$, assumed to be constant throughout, which quantifies its resistance to relative motion between layers.

The strain rate tensor is defined as the quantity

$$
\frac{1}{2}\left(\nabla \mathbf{v}+\nabla \mathbf{v}^{T}\right)
$$

We make certain simplifying assumptions about the fluid in consideration.

First, we assume that the fluid is incompressible. This means through any given volume, the total mass flowing in is equal to the total mass flowing out at any instance. In other words, the density of the fluid, say $\rho$, is considered a constant. This results in the continuity equation

$$
\nabla \cdot \mathbf{v}=0
$$

Secondly, the fluid is assumed to be Newtonian. This means the viscous stress, that is the part of the stress accompanying the strain rate, is directly proportional to the strain rate tensor. For an incompressible fluid, this results in the total stress tensor field being

$$
\boldsymbol{\sigma}=-p \mathbf{I}+\mu\left(\nabla \mathbf{v}+\nabla \mathbf{v}^{T}\right) .
$$

Note that

$$
\frac{\mathrm{d}}{\mathrm{d} t} \mathbf{v}(\mathbf{x}, t)=\frac{\partial}{\partial t} \mathbf{v}(\mathbf{x}, t)+\frac{\partial \mathbf{x}}{\partial t} \cdot \nabla \mathbf{v}(\mathbf{x}, t)=\frac{\partial}{\partial t} \mathbf{v}(\mathbf{x}, t)+\mathbf{v}(\mathbf{x}, t) \cdot \nabla \mathbf{v}(\mathbf{x}, t)
$$

and

$$
\nabla \cdot\left(\nabla \mathbf{v}+\nabla \mathbf{v}^{T}\right)=\Delta \mathbf{v}
$$

due to $\mathbf{v}$ being divergence free.

Let $\mathbf{g}$ be the acceleration due to gravity. Then, as in the previous section, by Newton's second law of motion,

$$
\begin{gathered}
\rho \frac{\mathrm{d} \mathbf{v}}{\mathrm{d} t}=\nabla \cdot \boldsymbol{\sigma}+\rho \mathbf{g} \\
\Leftrightarrow \frac{\partial \mathbf{v}}{\partial t}+v \cdot \nabla \mathbf{v}=-\frac{1}{\rho} \nabla p+\frac{\mu}{\rho} \Delta \mathbf{v}+\mathbf{g} .
\end{gathered}
$$

The preceding equation is called the Navier-Stokes equation. As the density of the fluid is taken to be constant, the pressure $p$ can be replaced by the kinematic pressure $q=\frac{p}{\rho}$ and instead of the dynamic viscosity $\mu$, kinematic viscosity $\nu=\frac{\mu}{\rho}$ can be used. 
The Reynolds number is a dimensionless quantity signifying the ratio of inertial forces to viscous forces associated with a flow. It also signifies the transition of a flow from laminar to turbulent. A low value of the Reynolds number can be achieved by high values of viscosity or low velocities among other factors. In such cases, the viscous forces are dominating and hence the inertial terms in the Navier-Stokes equation can be neglected to obtain

$$
-\nu \Delta \mathbf{v}+\nabla q=\mathbf{g}
$$

This is called the Stokes equation and the flow described by it is called the Stokes flow.

In our work, the modelling of the flow is based either on the Stokes equation or on the linearized (neglecting only the non-linear term) Navier-Stokes equation. 


\section{Curvilinear coordinates}

In many modelling problems, the choice of a coordinate system proves to be crucial as it greatly affects the ease with which we can carry out computations. Sometimes, this choice for the 'most suitable' coordinate system is made simpler by the underlying geometry of the modelling assignment. In this chapter, some coordinate systems suitable to the modelling of curvilinear pipes are presented. The accompanying formulas necessary for calculus in these coordinate systems are also provided. The articles included in the thesis rely heavily on versions of the computations presented in this chapter.

The aim is to choose a suitable coordinate system that simplifies the computations even in the case of the most general geometry of the tube. As is the case with the subsequent articles, it is assumed that a canonical Cartesian coordinate system describes the space containing the vessel and a 'centre' curve of the vessel is known and given by an arclength perameterised curve $\mathbf{c} \in \mathcal{C}^{2}\left([0, L], \mathbb{R}^{3}\right)$ for some positive real $L$ that represents the total length of the considered tube. Without loss of generality, we may assume the initial conditions

$$
\mathbf{c}(0)=(0,0,0)^{T} \text { and } \mathbf{c}^{\prime}(0)=(0,0,1)^{T} .
$$

Here and henceforth, if a function, say $f$, depends only on one variable, we denote its derivative by $f^{\prime}$. Let the arc-length parameter be denoted by $s$. We use the centre curve to develop the required coordinate frames.

\subsection{Rotation minimizing frame}

At first, we need to build a right handed coordinate frame at each point $\mathbf{c}(s)$. The coordinate system should be the cylindrical coordinate system in the special case of a straight cylinder, that is, when $\mathbf{c}^{\prime \prime}(s) \equiv 0$. It is natural to take one of the coordinate directions to be $\mathbf{c}^{\prime}(s)$ and the other two to be perpendicular to it. A natural choice is to use the FrenetSerret frame. This has the obvious problem that it is not defined when the curvature vanishes.

Let $\mathbf{e}_{1}$ be one such unit vector perpendicular to $\mathbf{c}^{\prime}$ at each $s$. We could use the Frenet-Serret frame to define $\mathbf{e}_{1}(\theta, s)=\cos \theta \mathbf{N}(s)-\sin \theta \mathbf{B}(s)$ where $\mathbf{N}$ and $\mathbf{B}$ are the unit normal and the unit binormal of the curve $\mathbf{c}$, if we assume that the curve has non-vanishing curvature. 
Consider the surface $S(\theta, s)=\mathbf{c}(s)+r_{\delta} \mathbf{e}_{1}(\theta, s)$ for some $r_{\delta}>0$. The surface $S$ is a pipe around the centre curve so that every point on it has a constant distance $r_{\delta}$ from the centre curve. Then,

$$
\begin{aligned}
& \frac{\partial S(\theta, s)}{\partial \theta}=-\sin \theta \mathbf{N}(s)-\cos \theta \mathbf{B}(s), \\
& \frac{\partial S(\theta, s)}{\partial s}=\cos \theta\left(-\kappa(s) \mathbf{c}^{\prime}(s)+\tau(s) \mathbf{B}(s)\right)+\tau(s) \mathbf{N}(s),
\end{aligned}
$$

where $\kappa$ and $\tau$ are the curvature and torsion respectively of the curve c. Hence

$$
\frac{\partial S(\theta, s)}{\partial \theta} \cdot \frac{\partial S(\theta, s)}{\partial s}=-\tau(s)
$$

As the partial derivatives of $S$ with respect to $\theta$ and $s$ give us the coordinate directions for the respective parameters, we conclude that the corresponding coordinate lines do not intersect at right angles when $\mathbf{c}$ has nonzero torsion. For this reason, we reject this choice of coordinate frame.

A better choice proves to be one that is based on the requirement that the change in $\mathbf{e}_{1}$ as we travel along the central curve, should be coplanar with $\mathbf{e}_{1}$ and $\mathbf{c}^{\prime}(s)$, that is, $\partial_{s} \mathbf{e}_{1} \cdot\left(\mathbf{e}_{1} \times \mathbf{c}^{\prime}\right)=0$. This prevents the coordinate lines corresponding to $s$ from 'wrapping around' the tubular surface due to torsion of the centre curve. Since $\mathbf{e}_{1}$ is a unit vector, we have

$$
\partial_{s} \mathbf{e}_{1} \cdot \mathbf{e}_{1}=\frac{1}{2} \partial_{s}\left\|\mathbf{e}_{1}(s)\right\|^{2}=0 .
$$

Also, as $\mathbf{c}^{\prime}$ is perpendicular to $\mathbf{e}_{1}$ at each $s$, it follows that

$$
\partial_{s}\left(\mathbf{e}_{1} \cdot \mathbf{c}^{\prime}\right)=0 \Leftrightarrow \partial_{s} \mathbf{e}_{1} \cdot \mathbf{c}^{\prime}=-\mathbf{c}^{\prime \prime} \cdot \mathbf{e}_{1} .
$$

Therefore, the coplanarity condition on the vector $\partial_{s} \mathbf{e}_{1}$ with the orthonormal vectors $\left\{\mathbf{c}^{\prime}, \mathbf{e}_{1}\right\}$ is equivalent to

$$
\partial_{s} \mathbf{e}_{1}=\left(\partial_{s} \mathbf{e}_{1} \cdot \mathbf{c}^{\prime}\right) \mathbf{c}^{\prime}+\left(\partial_{s} \mathbf{e}_{1} \cdot \mathbf{e}_{1}\right) \mathbf{e}_{1}=-\left(\mathbf{c}^{\prime \prime} \cdot \mathbf{e}_{1}\right) \mathbf{c}^{\prime}
$$

We choose the initial value of $\mathbf{e}_{1}$ at $s=0$ to be $(\cos \theta, \sin \theta, 0)^{T}$ for some $\theta \in[0,2 \pi]$. Then we obtain the following initial value problem that defines $\mathbf{e}_{1}$

$$
\partial_{s} \mathbf{e}_{1}(\theta, s)=-\left(\mathbf{c}^{\prime \prime}(s) \cdot \mathbf{e}_{1}(\theta, s)\right) \mathbf{c}^{\prime}(s) \text { and } \mathbf{e}_{1}(\theta, 0)=(\cos \theta, \sin \theta, 0)^{T} .
$$

Defining $\mathbf{e}_{2}(\theta, s)=\mathbf{c}^{\prime}(s) \times \mathbf{e}_{1}(\theta, s)$, the triple $\left\{\mathbf{e}_{1}(\theta, s), \mathbf{e}_{2}(\theta, s), \mathbf{c}^{\prime}\right\}$ forms an orthonormal frame at each point $\mathbf{c}(s)$ for a given angle $\theta$. As a result, we have

$$
\begin{aligned}
\partial_{s} \mathbf{e}_{2}(\theta, s) & =\mathbf{c}^{\prime \prime}(s) \times \mathbf{e}_{1}(\theta, s)+\mathbf{c}^{\prime}(s) \times \partial_{s} \mathbf{e}_{1}(\theta, s)=\mathbf{c}^{\prime \prime}(s) \times\left(\mathbf{e}_{2}(\theta, s) \times \mathbf{c}^{\prime}(s)\right) \\
& =\mathbf{c}^{\prime \prime}(s) \cdot \mathbf{c}^{\prime}(s) \mathbf{e}_{2}(\theta, s)-\mathbf{c}^{\prime \prime}(s) \cdot \mathbf{e}_{2}(\theta, s) \mathbf{c}^{\prime}(s)=-\mathbf{c}^{\prime \prime}(s) \cdot \mathbf{e}_{2}(\theta, s) \mathbf{c}^{\prime}(s) .
\end{aligned}
$$


The initial condition for $\mathbf{e}_{2}$ reads

$$
\mathbf{e}_{2}(\theta, 0)=\mathbf{c}^{\prime}(0) \times \mathbf{e}_{1}(\theta, 0)=(-\sin \theta, \cos \theta, 0)^{T} .
$$

So we obtain

$$
\partial_{s} \mathbf{e}_{2}(\theta, s)=-\left(\mathbf{c}^{\prime \prime}(s) \cdot \mathbf{e}_{2}(\theta, s)\right) \mathbf{c}^{\prime}(s) \text { and } \mathbf{e}_{2}(\theta, 0)=(-\sin \theta, \cos \theta, 0)^{T} .
$$

The equations (3.2) and (3.3) ensure that the frame $\left\{\mathbf{c}^{\prime}, \mathbf{e}_{1}, \mathbf{e}_{2}\right\}$ is a so called 'rotation minimizing frame', see $[1,6]$.

One can define a rotation-matrix valued function $R$ so that $\mathbf{e}_{i}=R(s) \mathbf{e}_{i}(\theta, 0)$ for $i=1,2$. Then it is readily obtained that

$$
\partial_{\theta} \mathbf{e}_{1}(\theta, s)=\mathbf{e}_{2}(\theta, s) \text { and } \partial_{\theta} \mathbf{e}_{2}(\theta, s)=-\mathbf{e}_{1}(\theta, s) .
$$

The relations (3.2) and (3.3) can be represented in an analogous way to the Frenet-Serret frame as

$$
\partial_{s}\left[\begin{array}{c}
\mathbf{e}_{1} \\
\mathbf{e}_{2} \\
\mathbf{c}
\end{array}\right]=\left[\begin{array}{ccc}
0 & 0 & -\mathbf{c}^{\prime \prime} \cdot \mathbf{e}_{1} \\
0 & 0 & -\mathbf{c}^{\prime \prime} \cdot \mathbf{e}_{2} \\
\mathbf{c}^{\prime \prime} \cdot \mathbf{e}_{1} & \mathbf{c}^{\prime \prime} \cdot \mathbf{e}_{2} & 0
\end{array}\right]\left[\begin{array}{c}
\mathbf{e}_{1} \\
\mathbf{e}_{2} \\
\mathbf{c}
\end{array}\right]
$$

The parameter $\theta$ corresponds to the orientation of the vectors $\mathbf{e}_{1}(\theta, s)$ and $\mathbf{e}_{2}(\theta, s)$ for given $s$, with respect to some reference pair of orthogonal vectors in the same disc perpendicular to the corresponding tangent vector $\mathbf{c}^{\prime}(s)$ of the central curve. We assume it to be zero when $r=0$. Note that in the curvature free case, the orthonormal frame is the same as the cylindrical coordinate frame.

The relationship between the Cartesian and the new curvilinear coordinate systems are expressed as

$$
\mathbf{x}(r, \theta, s)=\mathbf{c}(s)+r \mathbf{e}_{1}(\theta, s)
$$

The scale factors associated with the curvilinear coordinates $\{r, \theta, s\}$ are defined as $H_{i}:=$ $\left\|\partial_{i} \mathbf{x}\right\|$ for the $i$-th coordinate. As a result,

$$
H_{r} \equiv 1, \quad H_{\theta}=r, \quad \text { and } \quad H_{s}=1-r \mathbf{c}^{\prime \prime} \cdot \mathbf{e}_{1} .
$$

The non-zero components of the metric tensor are

$$
g_{11}=H_{r}^{2}=1, \quad g_{22}=H_{\theta}^{2}=r^{2}, \quad g_{33}=H_{s}^{2}=\left(1-r \mathbf{c}^{\prime \prime} \cdot \mathbf{e}_{1}\right)^{2} .
$$

Hence, $\sqrt{\operatorname{det}(g)}=r\left(1-r \mathbf{c}^{\prime \prime} \cdot \mathbf{e}_{1}\right)$.

The nabla operator $\nabla$ in the new coordinates is given as

$$
\nabla=\frac{1}{H_{r}} \mathbf{e}_{1} \partial_{r}+\frac{1}{H_{\theta}} \mathbf{e}_{2} \partial_{\theta}+\frac{1}{H_{s}} \mathbf{c}^{\prime} \partial_{s}=\mathbf{e}_{1} \partial_{1}+\frac{1}{r} \mathbf{e}_{2} \partial_{\theta}+\frac{1}{1-r \mathbf{c}^{\prime \prime} \cdot \mathbf{e}_{1}} \mathbf{c}^{\prime} \partial_{s} .
$$


Keeping in mind the derivatives of the coordinate unit vectors with respect to the new coordinate variables, the Laplacian $\Delta=\nabla \cdot \nabla$ is given as

$$
\begin{aligned}
\Delta & =\partial_{1}^{2}+\frac{1}{r^{2}} \partial_{\theta}^{2}+\frac{1}{r} \partial_{1}-\frac{1}{1-r \mathbf{c}^{\prime \prime} \cdot \mathbf{e}_{1}} \mathbf{c}^{\prime \prime} \cdot\left(\mathbf{e}_{1} \partial_{1}+\frac{1}{r} \mathbf{e}_{2} \partial_{\theta}\right) \\
& +\frac{1}{\left(1-r \mathbf{c}^{\prime \prime} \cdot \mathbf{e}_{1}\right)^{2}} \partial_{s}^{2}+\frac{r \mathbf{c}^{\prime \prime} \cdot \mathbf{e}_{1}}{\left(1-r \mathbf{c}^{\prime \prime} \cdot \mathbf{e}_{1}\right)^{3}} \partial_{s} .
\end{aligned}
$$

Consider a vector field $\mathbf{v}=v_{1} \mathbf{e}_{1}+v_{2} \mathbf{e}_{2}+v_{3} \mathbf{c}^{\prime}$. The divergence of $\mathbf{v}$ becomes

$$
\nabla \cdot \mathbf{v}=\partial_{r} v_{1}+\frac{1}{r} \partial_{\theta} v_{2}+\frac{1}{1-r \mathbf{c}^{\prime \prime} \cdot \mathbf{e}_{1}} \partial_{s} v_{3}+\frac{v_{1}}{r}-\frac{\mathbf{c}^{\prime \prime} \cdot \mathbf{v}}{1-r \mathbf{c}^{\prime \prime} \cdot \mathbf{e}_{1}}
$$

\subsection{Non-orthogonal frame}

The reference frame $\left\{\mathbf{e}_{1}, \mathbf{e}_{2}, \mathbf{c}^{\prime}\right\}$ is sufficient to perform vector calculus with ease when modelling the flow through the interior of the pipes. However, it loses its efficiency when modelling the laminate wall of the pipe. Due to the customary ways of formulation of the physical laws, it is desirable to have simple expressions for the normal vectors to each layer. In general, the vector field $\mathbf{e}_{1}$ is not aligned with the normal vectors of the layers due to the variable width of the channel or that of the wall. In such cases, the computations are simplified by using a non-orthogonal frame to describe the vector fields.

A detailed presentation of tensor algebra in curvilinear coordinates for application to continuum mechanics can be found in Appendix D of [9].

Let there be new coordinates $\left\{q^{1}, q^{2}, q^{3}\right\}$ having the desired properties. Let us define $\partial_{i}=\partial / \partial q^{i}$ for $i \in\{1,2,3\}$. Also, we adopt Einstein's summation convention, that is, repeated indices, when appearing concurrently at both the top and bottom positions in a term, are assumed to be summed over the index set, which is $\{1,2,3\}$ in our case.

We now define a set of contravariant basis vectors for tangent vectors. Let $\mathbf{x}_{i}=\partial_{i} \mathbf{x}$ for $i=1,2,3$ and position vector $\mathbf{x}\left(q^{1}, q^{2}, q^{3}\right)$. We can define (the metric tensor having coefficients) $g_{i j}=\mathbf{x}_{i} \cdot \mathbf{x}_{j}$ for $i, j=1,2,3$. Let $g$ denote the matrix $\left[g_{i j}\right]$.

We may also define a set of covariant or reciprocal basis vectors for the same space (cf. Appendix D of [9]) which are given as $\mathbf{x}^{i}=g^{i j} \mathbf{x}_{j}$ where $g^{i j}$ is such that $g^{i j} g_{j k}=\delta_{k}^{i}$ with $\delta_{k}^{i}$ being the Kronecker delta. Note that the contravariant basis vectors have bottom indices while the reciprocal basis vectors have top indices. By definition, $\mathbf{x}^{i}$ is perpendicular to both $\mathbf{x}_{j}$ and $\mathbf{x}_{k}$ for each permutation $(i, j, k)$ of $(1,2,3)$. This means for suitable a choice of coordinates $\left\{q^{1}, q^{2}, q^{3}\right\}, \mathbf{x}^{1}$ is automatically normal to any surface defined by a fixed $q^{1}$. This makes it easier for us to formulate the physical laws. 
In order to express derivatives in a curvilinear system, we need the Christoffel symbols corresponding to the curvilinear system which are defined as $\Gamma_{j k}^{i}=\mathbf{x}^{i} \cdot \partial_{j} \mathbf{x}_{k}$ for $i, j, k=$ $1,2,3$. They quantify the change in the coordinate directions with derivation and are symmetric in the lower indices, i.e., $\Gamma_{j k}^{i}=\Gamma_{k j}^{i}$.

With the help of these relations, we can define the gradient operator as $\nabla=\mathbf{x}^{i} \partial_{i}$, see Appendix $\mathrm{E}$ in [9]. We are now in a position to express quantities like gradient and divergence of tensors in our curvilinear coordinates. For any vector $\mathbf{v}=v_{j} \mathbf{x}^{j}=v^{k} \mathbf{x}_{k}$, its gradient is given as

$$
\nabla \mathbf{v}=\left(\partial_{i} v_{j}-\Gamma_{i j}^{k} v_{k}\right) \mathbf{x}^{i} \mathbf{x}^{j}=\left(\partial_{i} v^{k}+\Gamma_{i j}^{k} v^{j}\right) \mathbf{x}^{i} \mathbf{x}_{k}
$$

The divergence of the vector $\mathbf{v}$ is given as

$$
\begin{aligned}
\nabla \cdot \mathbf{v} & =g^{i j}\left(\partial_{i} v_{j}-\Gamma_{i j}^{k} v_{k}\right)=\partial_{i} v^{i}+\Gamma_{i j}^{i} v^{j} \\
& =(\sqrt{\operatorname{det}(g)})^{-1} \partial_{i}\left(\sqrt{\operatorname{det}(g)} v^{i}\right)
\end{aligned}
$$

where $\operatorname{det}(\cdot)$ denotes the determinant.

The Laplacian is then defined as

$$
\Delta=\nabla \cdot \nabla=g^{i j}\left(\partial_{i} \partial_{j}-\Gamma_{i j}^{k} \partial_{k}\right) .
$$

Consequently, the Laplacian of the vector $\mathbf{v}$ can be given as

$$
\begin{aligned}
\Delta \mathbf{v} & =g^{i j}\left[\partial_{i} \partial_{j} v_{k}-\Gamma_{i j}^{l} \partial_{l} v_{k}-\Gamma_{i k}^{l} \partial_{j} v_{l}-\Gamma_{k j}^{l} \partial_{i} v_{l}\right. \\
& \left.-\left(\partial_{i} \Gamma_{k j}^{l}-\Gamma_{k m}^{l} \Gamma_{i j}^{m}-\Gamma_{m j}^{l} \Gamma_{k i}^{m}\right) v_{l}\right] \mathbf{x}^{k} \\
& =g^{i j}\left[\partial_{i} \partial_{j} v^{k}-\Gamma_{i j}^{l} \partial_{l} v^{k}+\Gamma_{i l}^{k} \partial_{j} v^{l}+\Gamma_{l j}^{k} \partial_{i} v^{l}\right. \\
& \left.+\left(\partial_{i} \Gamma_{l j}^{k}-\Gamma_{l m}^{k} \Gamma_{i j}^{m}+\Gamma_{m i}^{k} \Gamma_{l j}^{m}\right) v^{l}\right] \mathbf{x}_{k} .
\end{aligned}
$$

Also, for any rank 2 tensor $\sigma=\sigma^{i j} \mathbf{x}_{i} \mathbf{x}_{j}=\sigma^{i}{ }_{j} \mathbf{x}_{i} \mathbf{x}^{j}=\sigma_{i}{ }^{j} \mathbf{x}^{i} \mathbf{x}_{j}=\sigma_{i j} \mathbf{x}^{i} \mathbf{x}^{j}$, its divergence is expressed as

$$
\begin{aligned}
\nabla \cdot \sigma & =\left(\partial_{i} \sigma^{i k}+\Gamma_{i j}^{i} \sigma^{j k}+\Gamma_{i j}^{k} \sigma^{i j}\right) \mathbf{x}_{k} \\
& =\left(\partial_{i} \sigma_{k}^{i}+\Gamma_{i j}^{i} \sigma^{j}{ }_{k}-\Gamma_{i k}^{j} \sigma^{i}{ }_{j}\right) \mathbf{x}^{k} \\
& =\left(\partial_{i} \sigma_{j}^{k}-\Gamma_{i j}^{l} \sigma_{l}{ }^{k}+\Gamma_{i l}^{k} \sigma_{j}^{l}\right) g^{i j} \mathbf{x}_{k} \\
& =\left(\partial_{i} \sigma_{j k}-\Gamma_{i j}^{l} \sigma_{l k}-\Gamma_{i k}^{l} \sigma_{j l}\right) g^{i j} \mathbf{x}^{k} .
\end{aligned}
$$

\subsection{Volume and area elements}

The derivation of the final model equations involve integration of certain scalar or vector quantities over the entire three-dimensional channel or the two-dimensional surface bounding the channel or across a cross-section of the pipe. To enable such operations, the volume and area elements are required to be specified in the new coordinates. 
The volume of a parallelepiped formed by the basis vectors $\left\{\mathbf{x}_{1}, \mathbf{x}_{2}, \mathbf{x}_{3}\right\}$ as sides is given by

$$
\operatorname{det}\left(\left[\mathbf{x}_{1}, \mathbf{x}_{2}, \mathbf{x}_{3}\right]\right)=\sqrt{\operatorname{det}\left(\left[\mathbf{x}_{1}, \mathbf{x}_{2}, \mathbf{x}_{3}\right]^{T}\left[\mathbf{x}_{1}, \mathbf{x}_{2}, \mathbf{x}_{3}\right]\right)}=\sqrt{\operatorname{det}(g)} .
$$

Hence, the infinitesimal volume element with respect to the new variables is

$$
\mathrm{d} V=\sqrt{\operatorname{det}(g)} \mathrm{d} q^{1} \mathrm{~d} q^{2} \mathrm{~d} q^{3},
$$

where the superscript $[\cdot]^{T}$ denotes the transpose.

On the other hand, the area of the parallelogram formed by the basis vectors $\left\{\mathbf{x}_{2}, \mathbf{x}_{3}\right\}$ as sides is given by

$$
\left|\mathbf{x}_{2} \times \mathbf{x}_{3}\right|=\sqrt{\left|\mathbf{x}_{2}\right|^{2}\left|\mathbf{x}_{3}\right|^{2}-\left(\mathbf{x}_{2} \cdot \mathbf{x}_{3}\right)^{2}}=\sqrt{g_{22} g_{33}-\left(g_{23}\right)^{2}}=\sqrt{g^{11} \operatorname{det}(g)} .
$$

Hence, the infinitesimal surface element on a surface with fixed $q^{1}$ is

$$
\mathrm{d} S^{1}=\sqrt{g^{11} \operatorname{det}(g)} \mathrm{d} q^{2} \mathrm{~d} q^{3} .
$$

Similarly for $\mathrm{d} S^{2}$ and $\mathrm{d} S^{3}$. 


\section{Asymptotic analysis}

The central theme in our modelling of thin pipes is the use of asymptotic methods. Such methods use a small parameter that occurs in a given problem, to solve the problem. In this chapter, some basic concepts of the asymptotic method employed in the included works are presented. An overview on perturbation methods can be found in [10].

\subsection{Asymptotic approximation}

Here, the order of a function is defined and subsequently the phrase 'asymptotic expansion of a function' is formalized.

Definition 4.1.1. A function $f(\varepsilon)$ is said to be of the order of $g(\varepsilon)$ and written as $f(\varepsilon)=$ $O(g(\varepsilon))$ as $\varepsilon \rightarrow 0$ iff

$$
\lim _{\varepsilon \rightarrow 0}\left|\frac{f(\varepsilon)}{g(\varepsilon)}\right|<\infty .
$$

On the other hand, $f(\varepsilon)=o(g(\varepsilon))$ iff

$$
\lim _{\varepsilon \rightarrow 0}\left|\frac{f(\varepsilon)}{g(\varepsilon)}\right|=0 .
$$

For the asymptotic methods employed in the articles included in this thesis, it suffices to define the asymptotic expansion of a function in the following way.

Definition 4.1.2. A function $f$ is said to have an asymptotic expansion of $N$ terms with respect to $\varepsilon$ and given as $\varepsilon^{N_{0}} \sum_{n=0}^{N-1} f_{n} \varepsilon^{n}$ for some $N_{0} \in \mathbb{Z}$, if

$$
f-\varepsilon^{N_{0}} \sum_{n=0}^{M} f_{n} \varepsilon^{n}=o\left(\varepsilon^{N_{0}+M}\right) \quad \text { as } \quad \varepsilon \rightarrow 0,
$$

for each $M=0,1, \cdots, N-1$ with coefficients $f_{n}=O\left(\varepsilon^{0}\right)$.

It is not necessary for the partial sums considered above to converge as $N \rightarrow \infty$. The more terms are included in the expansion, the better approximation of the function $f$ is obtained for $\varepsilon \rightarrow 0$. 


\subsection{Method of slow variation}

In the case of thin pipes, the natural small parameter (say $\varepsilon$ ) is its aspect ratio, that is, the ratio of its width to its length. The physical quantities vary rapidly in the transverse direction as compared to the longitudinal direction. Hence a stretching of variables is introduced for the transverse direction through a scaling by $\varepsilon^{-1}$. As a result, the differential operators are also modified.

As an example, let $L$ be a differential operator and $v(x, y)$ be a function satisfying $L v=0$ with appropriate boundary conditions. Letting $x$ to be the transversal variable, introduce the stretched variable $x^{\prime}=\varepsilon^{-1} x$. Then, in terms of the new variable, we have for some $N \in \mathbb{Z}$, a decomposition

$$
L=\varepsilon^{N}\left(L_{0}+\varepsilon L_{1}+\varepsilon^{2} L_{2}+\ldots\right) .
$$

Meanwhile, a formal asymptotic expansion of $v$ is assumed in the form of

$$
v(x, y)=\varepsilon^{M}\left(v_{0}\left(x^{\prime}, y\right)+\varepsilon v_{1}\left(x^{\prime}, y\right)+\varepsilon^{2} v_{2}\left(x^{\prime}, y\right)+\ldots\right)
$$

for some $M \in(Z)$.

The last step is to match the coefficients of different orders of $\varepsilon$ in the equation obtained by replacing the expansions in the original equation. In particular, a series of equations are obtained which have the form

$$
\begin{aligned}
& L_{0} v_{0}\left(x^{\prime}, y\right)=0 \\
& L_{0} v_{1}\left(x^{\prime}, y\right)=-L_{1} v_{0}\left(x^{\prime}, y\right) \\
& L_{0} v_{2}\left(x^{\prime}, y\right)=-L_{2} v_{0}\left(x^{\prime}, y\right)-L_{1} v_{1}\left(x^{\prime}, y\right)
\end{aligned}
$$

These equations are successively solved with the corresponding boundary conditions to get the desired order of approximation of the solution to the original equation. 


\section{References}

[1] R. L. Bishop. There is more than one way to frame a curve. The American Mathematical Monthly, 82:246-251, 1975.

[2] P. Fratzl, editor. Collagen: Structure and Mechanics. Springer US, 2008.

[3] Y. C. Fung. Biomechanics: Circulation. Springer-Verlag New York, 1997.

[4] L. Grinberg, E. Cheever, T. Anor, J. R. Madsen, and G. E. Karniadakis. Modeling blood flow circulation in intracranial arterial networks: A comparative 3d/1d simulation study. Annals of Biomedical Engineering, 39(1):297-309, Jan 2011.

[5] J. B. Grotberg and O. E. Jensen. Biofluid mechanics in flexible tubes. In Annual review of fluid mechanics. Vol. 36, volume 36 of Annu. Rev. Fluid Mech., pages 121147. Annual Reviews, Palo Alto, CA, 2004.

[6] F. Klok. Two moving coordinate framesfor sweeping along a 3d trajectory. Computer Aided Geometric Design, 3:217-229, 1986.

[7] W. M. Lai, D. Rubin, and E. Krempl. Introduction to Continuum Mechanics. Butterworth-Heinemann, Boston, fourth edition, 2010.

[8] J. Lighthill. Mathematical biofluiddynamics. Society for Industrial and Applied Mathematics, Philadelphia, Pa., 1975. Based on the lecture course delivered to the Mathematical Biofluiddynamics Research Conference of the National Science Foundation held from July 16-20, 1973, at Rensselaer Polytechnic Institute, Troy, New York, Regional Conference Series in Applied Mathematics, No. 17.

[9] A. I. Lurie. Theory of Elasticity. Springer, 2005.

[10] R. M. M. Mattheij, S. W. Rienstra, and J. H. M. ten Thije Boonkkamp. Partial differential equations. SIAM Monographs on Mathematical Modeling and Computation. Society for Industrial and Applied Mathematics (SIAM), Philadelphia, PA, 2005. Modeling, analysis, computation.

[11] T. J. Pedley. Mathematical modelling of arterial fluid dynamics. J. Engrg. Math., 47(3-4):419-444, 2003. Mathematical modelling of the cardiovascular system.

[12] A. Quarteroni and L. Formaggia. Mathematical modelling and numerical simulation of the cardiovascular system. In Handbook of numerical analysis. Vol. XII, Handb. Numer. Anal., XII, pages 3-127. North-Holland, Amsterdam, 2004.

[13] A. Quarteroni, M. Tuveri, and A. Veneziani. Computational vascular fluid dynamics: Problems, models and methods. Comput. Vis. Sci., 2(4):163-197, mar 2000. 
[14] P. Reymond, Y. Bohraus, F. Perren, F. Lazeyras, and N. Stergiopulos. Validation of a patient-specific one-dimensional model of the systemic arterial tree. American Journal of Physiology - Heart and Circulatory Physiology, 301(3):H1173-H1182, 2011.

[15] C. A. Taylor and M. T. Draney. Experimental and computational methods in cardiovascular fluid mechanics. In Annual review of fluid mechanics. Vol. 36, volume 36 of Annu. Rev. Fluid Mech., pages 197-231. Annual Reviews, Palo Alto, CA, 2004.

[16] S. Canić and A. Mikelić. Effective equations modeling the flow of a viscous incompressible fluid through a long elastic tube arising in the study of blood flow through small arteries. SIAM J. Appl. Dyn. Syst., 2(3):431-463, 2003.

[17] S. Čanić, J. Tambača, G. Guidoboni, A. Mikelić, C. J. Hartley, and D. Rosenstrauch. Modeling viscoelastic behavior of arterial walls and their interaction with pulsatile blood flow. SIAM J. Appl. Math., 67(1):164-193, 2006. 


\section{Papers}

The papers associated with this thesis have been removed for copyright reasons. For more details about these see:

http://urn.kb.se/resolve?urn=urn:nbn:se:liu:diva-156346 


\section{FACULTY OF SCIENCE AND ENGINEERING}

Linköping Studies in Science and Technology, Dissertation No. 1988, 2019 Department of Mathematics

Linköping University

SE-581 83 Linköping, Sweden

WWw.liu.se 